Sang-Yeop Chung, Mohamed Abd Elrahman, Ji-Su Kim, Tong-Seok Han, Dietmar Stephan, Pawel Sikora

\title{
Comparison of lightweight aggregate and foamed concrete with the same density level using image-based characterizations
}

Journal article | Accepted manuscript (Postprint)

This version is available at https://doi.org/10.14279/depositonce-11439

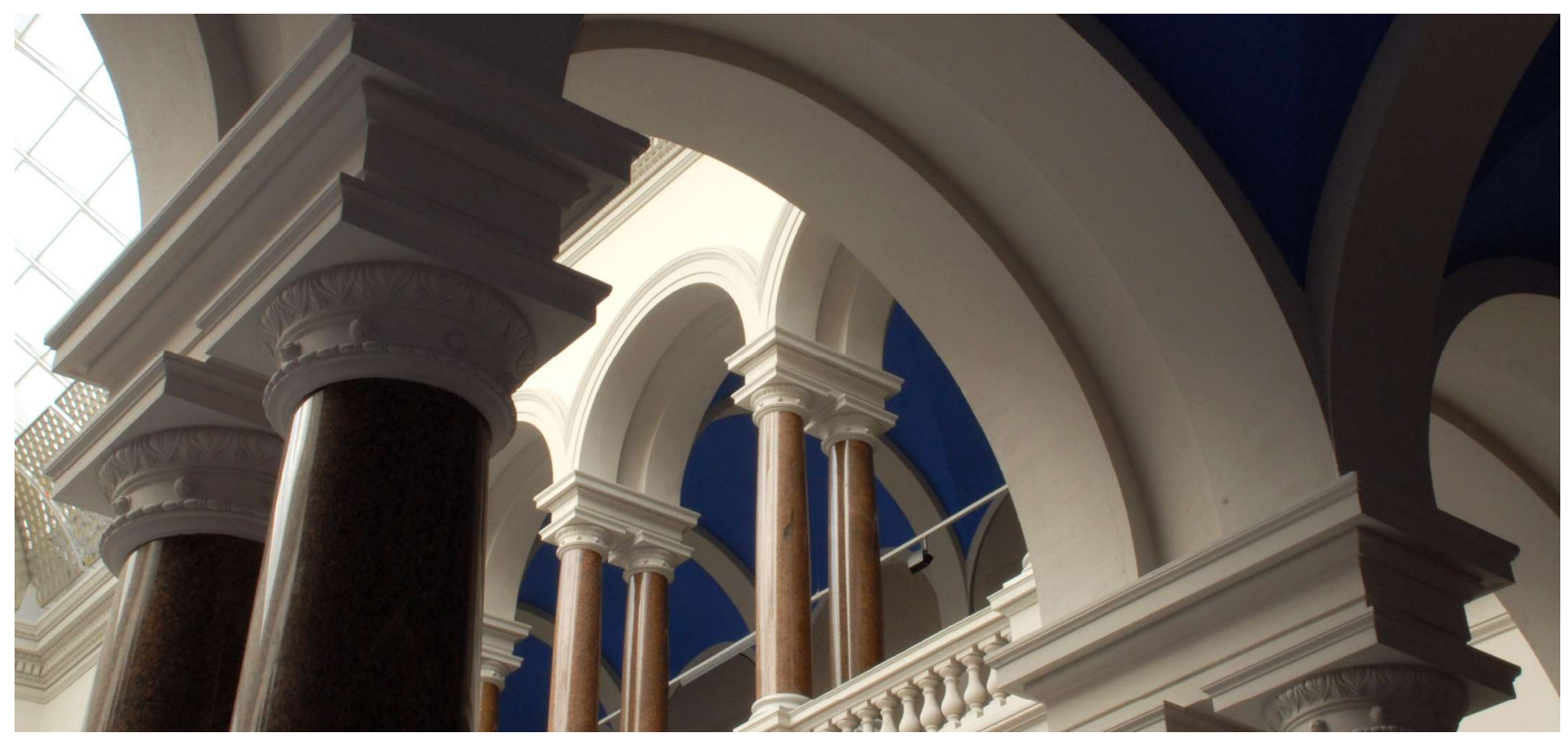

Chung, S.-Y., Abd Elrahman, M., Kim, J.-S., Han, T.-S., Stephan, D., \& Sikora, P. (2019). Comparison of lightweight aggregate and foamed concrete with the same density level using image-based characterizations. Construction and Building Materials, 211, 988-999.

https://doi.org/10.1016/j.conbuildmat.2019.03.270 


\title{
Comparison of lightweight aggregate and foamed concrete with
}

\section{the same density level using image-based characterizations}

\author{
Sang-Yeop Chung ${ }^{1,2}$, Mohamed Abd Elrahman ${ }^{1,4 *}$ Ji-Su Kim $^{3}$, Tong-Seok Han ${ }^{3}$, \\ Dietmar Stephan ${ }^{1}$, Pawel Sikora ${ }^{1,5}$ \\ ${ }^{1}$ Building Materials and Construction Chemistry, Technische Universität Berlin, \\ Gustav-Meyer-Allee 25, 13355 Berlin, Germany \\ ${ }^{2}$ Department of Civil and Environmental Engineering, Sejong University, \\ 209 Neungdong-ro, Gwangjin-gu, Seoul 05006, Republic of Korea \\ ${ }^{3}$ Department of Civil and Environmental Engineering, Yonsei University, \\ 50 Yonsei-ro, Seodamun-gu, Seoul 03722, Republic of Korea \\ ${ }^{4}$ Structural Engineering Department, Mansoura University, \\ Elgomhouria St., Mansoura City 35516, Egypt \\ ${ }^{5}$ Faculty of Civil Engineering and Architecture, West Pomeranian University of Technology Szczecin,
} Al. Piastow 50, Szczecin 70-311, Poland

\begin{abstract}
Lightweight concrete is a special type of concrete with low density and advanced insulation, mainly produced using lightweight aggregates or a cellular matrix. Concrete material made of lightweight aggregates is called lightweight aggregate concrete, while material made from a cellular matrix is generally called foamed concrete because of the pores introduced by a foaming agent. Both lightweight concrete types have different characteristics due to their different compositions. In this study, the material properties and characteristics of these lightweight concretes were investigated and compared. A series of foamed and lightweight aggregate concrete specimens with the same density level were produced, with their mechanical and thermal properties being evaluated using sensitive measurement tools. X-ray micro-computed tomography ( $\mu$-CT) and scanning electron microscopy (SEM) were used to characterize each material, using image-based techniques. The results brought to light the details of each lightweight concrete, at the microstructural level, in regard to their material properties and showed that the properly designed lightweight aggregate concrete can be more beneficial in mechanical performance by minimizing the loss of the insulation.
\end{abstract}

Keywords: lightweight aggregate concrete, foamed concrete, X-ray $\mu$-CT, SEM, density, compressive strength, thermal conductivity

\footnotetext{
${ }^{*}$ Corresponding author. Tel.: +49-30-314-72-104, Fax.:+49-30-314-72-110, E-mail: mohattia76@ gmail.com (M. Abd Elrahman)
} 


\section{Introduction}

Concrete, which has highly heterogeneous characteristics, is an essential material in the building and construction fields. Its material properties are strongly affected by randomly distributed components, such as hydrated/unhydrated phases and pores $[1,2]$. In addition to conventional Portland-cement concrete with normal aggregates, special types of concrete-such as self-compacting concrete, heavyweight concrete or lightweight concrete-have been developed for specific purposes, through the control of mixtures and admixtures $[3,4,5]$. One of these various special types of concrete, lightweight concrete (LWC), has been designed to reduce material density and to enhance thermal insulation $[6,7,8,9]$. In general, the density of LWC strongly affects its material properties; its density is in the range of 800 to $2000 \mathrm{~kg} / \mathrm{m}^{3}$ according to EN 206-1 [10], which is relatively lower than that of conventional concrete. Since energy efficiency and sustainability have become serious issues in the construction industry worldwide, LWC is being considered in terms of alleviating these problems.

LWC is generally produced by using natural/artificial lightweight aggregates $[11,12,13]$ or foaming agents $[14,15$, 16]; the former, with lightweight aggregates, is called lightweight aggregate concrete (LWAC), while the latter is called foamed concrete. Both LWC types show very low density and high insulation, as compared to conventional concrete. For LWAC, it is the characteristics of the lightweight aggregates which dominate in determining the properties of the resultant material, since they make up more than $50 \%$ of the concrete volume and because various sources can be used to produce them. For example, lightweight materials such as expanded clay [17], expanded shale [18], expanded glass [19] or crushed glass [20] can be used for making lightweight aggregate concrete because of their particular characteristics including low density. Notably, some of these materials are the result of recycling and can thus be used to reduce industrial waste. To reduce material density, it is important to include the maximal aggregate volume by minimizing the use of binder content. As such, the use of the proper grading of lightweight aggregate is very important, due to its effect on the density, workability and cost of concrete, with several studies having performed regarding aggregate grading $[6,19,21]$.

Foamed concrete (FC), another type of LWC, is a cellular lightweight concrete consisting of a cement matrix with a large number of pores. Since FC is a highly porous material with relatively low mechanical properties, it is used as a supplementary structural component for insulation and noise reduction purposes in general. The pores inside foamed concrete are induced by the use of a foaming agent or a chemical air-entraining agent and strongly affect its insulation performance and material properties [22,23]. As such, controlling the pore structure of foamed concrete is an important factor in determining its properties. The density of foamed concrete is in the range of 500 to $1500 \mathrm{~kg} / \mathrm{m}^{3}$, which is relatively low compared to that of LWAC and other types of concrete [24, 25]. Although FC is generally used 
for nonstructural purposes, it is necessary to satisfy certain minimum mechanical property requirements when it is to be used as part of a structure, with several researchers having looked into the material properties of foamed concrete. Hilal et al. [26] have investigated the effects of mineral additives on the strength of foamed concrete, and Nguyen et al. [27] have evaluated the influence of air-void characteristics on the compressive behavior of foamed concrete. Sayadi et al. [28] have used expanded polystyrene (EPS) particles to enhance the thermal and mechanical properties of foamed concrete, while Zhang et al. [29] have partially substituted fly ash with slag and demonstrated its effects improving the mechanical and thermal resistance properties of foamed concrete. These studies have demonstrated that both LWAC and FC are versatile building materials.

As representative LWCs, LWAC and FC have several similarities. Firstly, they are both hardly ever used as main structural components, because of their low mechanical properties. On the other hand, both LWAC and FC show very low conductive properties compared with conventional concrete; hence, both materials are widely used for enhancing the insulation and fire resistance. In addition, LWAC and FC have very low material density (less than $2000 \mathrm{~kg} / \mathrm{m}^{3}$ ) and are effective in reducing energy consumption. LWAC and FC have been adopted for improving the specific performance aspects of infrastructures, such as insulation [30, 31]. However, due to their differing compositions, these materials have different material characteristics, but both are required to meet certain minimum mechanical properties, so as to be effectively utilized as construction building materials. In general, LWAC is considered to have more advanced mechanical performance than FC, while the latter is known to be more effective in terms of reducing thermal conductivity, on account of its relatively lower material density and larger porosity. For a more detailed investigation of the advantages of each material, an appropriate comparison under the same conditions is required. However, most studies have focused only on LWAC or FC in isolation, with investigations comparing both materials having been conducted only rarely, despite both materials being in the same LWC category.

This study aims to investigate the material characteristics and properties of LWAC and FC, with the same density levels, using image-based methods to compare them. For this purpose, LWAC and FC specimens with 500, 750, and $1000 \mathrm{~kg} / \mathrm{m}^{3}$ densities were produced, respectively. To compare LWAC and FC, the material density, which is a dominant influence on the properties of concrete, was fixed. According to EN 206-1 [10], concrete with a density range of 800 to $2000 \mathrm{~kg} / \mathrm{m}^{3}$ is considered to be lightweight concrete, while a material with a density below $1000 \mathrm{~kg} / \mathrm{m}^{3}$ is classified as ultra-lightweight concrete, which can be used as a structural LWC [10]. Based on this standard, the specimens used here cover the range of both nonstructural (500 and $\left.750 \mathrm{~kg} / \mathrm{m}^{3}\right)$ and structural $\left(1000 \mathrm{~kg} / \mathrm{m}^{3}\right)$ lightweight concretes. To characterize the microstructures of the LWAC and FC specimens, X-ray micro-computed tomography ( $\mu$-CT) and scanning electron microscope (SEM) were adopted as image-based methods. Compared with other investigation methods that can damage the specimens during measurement, $\mu$-CT can visualize the microstructures and the 
quantitative structures of pores without damaging the materials, and SEM can provide the highlighted microstructural features. The mechanical and thermal properties of the specimens were evaluated using sensitive testing machines: Toni Technik (Germany) for compressive and flexural strength and a Hot Disk (Sweden) for thermal conductivity. The results obtained were examined to compare the performance of LWAC and FC, with the same density levels, from a microstructural point of view.

\section{Specimen preparation}

In this study, two types of concrete with the same density classes were prepared, in order to study the influence of different microstructures on their physical properties, at the same density level. Lightweight aggregate concrete (LWAC) with densities 500, 750, and $1000 \mathrm{~kg} / \mathrm{m}^{3}$ as well as foamed concrete with densities of 500, 750, and 1000 $\mathrm{kg} / \mathrm{m}^{3}$ were casted and tested. Several materials were used to produce these two types of concrete.

\subsection{Raw materials}

In order to focus on the effects of pore characteristics on FC and LWAC properties, cement type, content and w/b ratio were fixed for both concrete types. The cement used was CEM I 52.5 R according to EN 197-1 [32]. Condensed silica fume, which satisfies EN 13263-1 [33], was also used. At early ages, foamed concrete and lightweight aggregate concrete with low density are very weak and require longer period to completely harden. Incorporation of silica fume can significantly improve the compressive strength at early ages for both foamed concrete and lightweight aggregate concrete. In addition, silica fume can reduce the bleeding in the fresh state and improve the consistency as well as cohesion between aggregate and cement paste. The chemical composition and particle size distribution of the fine materials used have been presented in Table 1 and Fig. 1, respectively. For LWAC, expanded glass granulate (Liaver ${ }^{\circledR}$, LWA) was selected as a lightweight aggregate, from among several types of lightweight aggregates, because of its advanced physical properties $[19,34]$. Here, three different particle sizes of expanded glass aggregates were used: 0.5-1 mm, 1-2 mm, and 2-4 mm. An excess amount of water, equal to the aggregate absorption, was added to the mixing water to keep the w/b ratio constant for all the mixes, without affecting workability at the fresh state, due to the water absorption of lightweight aggregates. The properties of expanded glass aggregates have been presented in Table 2.

One of the main challenges in producing ultra-lightweight concrete is the difficulty of compaction when the material is vibrated; this is caused by the density difference between the constituents, which can lead to segregation and bleeding. Therefore, the concrete needs to have self-leveling ability to ensure that the samples are completely filled 
Table 1: Chemical composition and physical properties of cement and silica fume [wt.\%]

\begin{tabular}{|c||c|c|c|c|c|c|c|c||c|c|}
\hline Material & $\mathbf{C a O}$ & $\mathbf{S i O}_{2}$ & $\mathbf{A l}_{2} \mathbf{O}_{3}$ & $\mathbf{F e}_{2} \mathbf{O}_{3}$ & $\mathbf{M g O}$ & $\mathbf{N a}_{2} \mathbf{O}$ & $\mathbf{K}_{2} \mathbf{O}$ & $\mathbf{S O}_{3}$ & $\begin{array}{c}\text { Specific } \\
\text { density }\end{array}$ & $\begin{array}{c}\text { Surface } \\
\text { area } \\
{\left[\mathbf{c m}^{2} / \mathbf{g}\right]}\end{array}$ \\
\hline $\begin{array}{c}\text { CEM I 52.5 R } \\
\text { Silica fume }\end{array}$ & 63.14 & 20.53 & 5.33 & 2.36 & 1.49 & 0.21 & 0.72 & 3.39 & 3.05 & 3860 \\
\end{tabular}

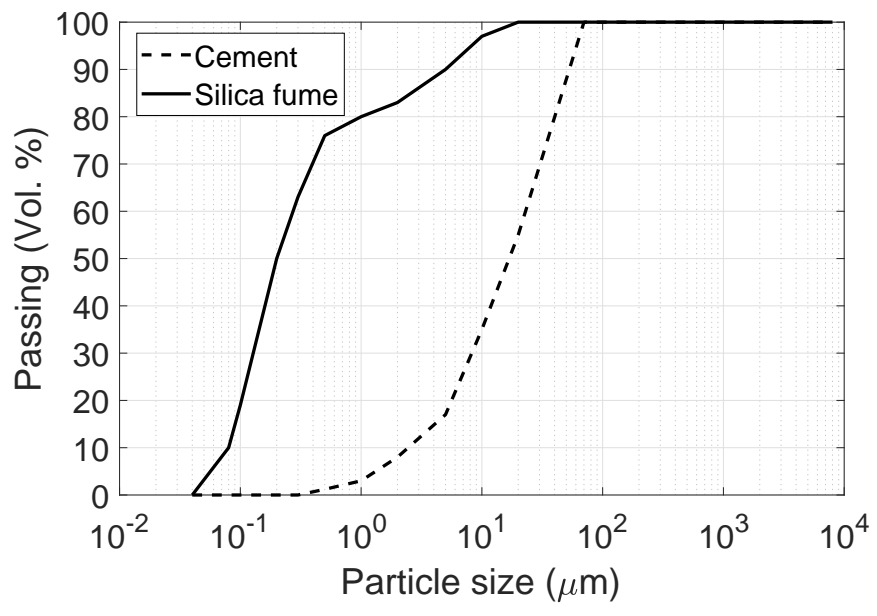

Figure 1: Particle size distributions of cement and silica fume

without large voids inside or on the surface. To achieve this, a polycarboxylic superplasticizer (Viscocrete 1051, Sika Germany) with a density of $1.04 \mathrm{~g} / \mathrm{m}^{3}$ was used to achieve a F4/F5 consistency class according to EN 206-1 [10]. In addition, a viscosity enhancing admixture (Sika Stabilizer) was used to prevent segregation and to improve mix stability and cohesion.

For the foamed concrete mixes, CEM I 52.5 R cement was used, as well as silica fume in powdered form. The foamed concrete specimens were produced using a foaming agent provided by Sika GmbH (Germany). Two parameters were considered in this investigation, so as to control the density of the foamed concrete: changing the foam:paste ratio, and adding fine quartz sand with a particle size of 0.1-0.3 mm. In this investigation, foamed concrete mixes was designed based on the concept that the chemically bound water is about $20 \mathrm{wt.} . \%$ [35]. The dry density of foamed concrete is the sum of the dry components plus the chemically bound water. In the mix calculation of foamed concrete, cement content, silica fume content and $\mathrm{w} / \mathrm{b}$ ratio were fixed for both concretes to have a fair comparison with LWAC. To compensate the difference between the densities of foam $\left(35 \mathrm{~kg} / \mathrm{m}^{3}\right)$ and lightweight aggregates $\left(330-460 \mathrm{~kg} / \mathrm{m}^{3}\right)$, fine quartz sand was used to achieve the same density of LWAC. After several trials, it was observed that the rheology of the cement slurry was one of the main factors affecting the properties of the foamed concrete in both fresh and 
Table 2: Physical properties of expanded glass aggregates (LWA)

\begin{tabular}{|c|c|c|c|}
\hline Material & $\begin{array}{c}\text { LWA } \\
0.5-1 \mathrm{~mm}\end{array}$ & $\begin{array}{c}\text { LWA } \\
1-2 \mathrm{~mm}\end{array}$ & $\begin{array}{c}\text { LWA } \\
2-4 \mathrm{~mm}\end{array}$ \\
\hline Particle density $\left[\mathrm{kg} / \mathrm{m}^{3}\right]$ & 460 & 420 & 330 \\
\hline Loose bulk density $\left[\mathrm{kg} / \mathrm{m}^{3}\right]$ & 250 & 220 & 190 \\
\hline Crushing resistance $\left[\mathrm{N} / \mathrm{mm}^{2}\right]$ & $\geq 2.6$ & $\geq 2.4$ & $\geq 2.1$ \\
\hline Water absorption [wt.\%] & 15.4 & 15.8 & 14.4 \\
\hline
\end{tabular}

Table 3: Composition of concrete mixes

\begin{tabular}{|c|c|c|c|c|c|c|c|c|c|c|}
\hline Mix & $\begin{array}{l}\text { Cement } \\
{\left[\mathrm{kg} / \mathrm{m}^{3}\right]}\end{array}$ & $\begin{array}{c}\text { Silica fume } \\
{\left[\mathrm{kg} / \mathrm{m}^{3}\right]}\end{array}$ & $\begin{array}{c}\text { LWA } \\
0.5-1 \mathrm{~mm}\end{array}$ & $\begin{array}{c}\text { LWA } \\
1-2 \mathrm{~mm}\end{array}$ & $\begin{array}{c}\text { LWA } \\
2-4 \mathrm{~mm}\end{array}$ & $\begin{array}{c}\mathbf{Q S}^{*} \\
{\left[\mathbf{k g} / \mathbf{m}^{3}\right]}\end{array}$ & $\begin{array}{c}\text { Water } \\
{\left[\mathrm{kg} / \mathrm{m}^{3}\right]}\end{array}$ & $\begin{array}{c}\mathbf{S P * *} \\
{\left[\mathrm{kg} / \mathbf{m}^{3}\right]}\end{array}$ & $\begin{array}{c}\text { ST**** } \\
{\left[\mathbf{k g} / \mathbf{m}^{3}\right]}\end{array}$ & $\begin{array}{l}\text { Foam } \\
{\left[1 / \mathbf{m}^{3}\right]}\end{array}$ \\
\hline LWAC500 & 198 & 22 & 102 & 74 & 76 & - & 110 & 5.4 & 0.9 & - \\
\hline LWAC750 & 405 & 45 & 91 & 58 & 62 & - & 225 & 4.8 & 0.7 & - \\
\hline LWAC1000 & 450 & 50 & 72 & 49 & 51 & 230 & 250 & 4.8 & 0.7 & - \\
\hline FC500 & 198 & 22 & - & - & - & 230 & 110 & 3.8 & 0.9 & 670 \\
\hline FC750 & 405 & 45 & - & - & - & 210 & 225 & 2.6 & 1.9 & 500 \\
\hline FC1000 & 450 & 50 & - & - & - & 400 & 250 & 2.8 & 2.5 & 420 \\
\hline
\end{tabular}

*QS: quartz sand, **SP: superplasticizer, ${ }^{* * * S T: \text { stabilizer }}$

hardened states. In addition, normal superplasticizer had to be used because of defoaming characteristics, which led to foam deterioration. Therefore, a tailor-made superplasticizer (Sika, Germany), without a defoaming effect, was used to adjust the flowability of the cement slurry. To overcome the instability of the foamed concrete mix, a foam concrete stabilizer (ST 3, Sika, Germany) was used.

\subsection{Mix proportioning and sample preparation}

In this study, six different mixes were prepared and tested. Three mixes with expanded glass were produced for LWAC, while the other mixes were of foamed concrete. Table 3 shows the compositions of all the mixes. The water/binder ratio was fixed at 0.5 for all the mixes. The cement content was constant in each density class for LWAC and foamed concrete. In all mixes, the silica fume content was $10 \%$ of the cement weight.

The LWAC mixing process was carried out using a bucket mixer without pre-soaking the aggregates. The consistency of the fresh concrete was confirmed using a slump flow procedure according to EN 206-1 [10], with the flow diameter of all the mixes being in the range of $500-600 \mathrm{~mm}$. The specimens were cast in cubic $(100 \times 100 \times 100 \mathrm{~mm})$ and prism $(40 \times 40 \times 120 \mathrm{~mm})$ molds for different tests: the former for compressive strength and thermal conductivity and the latter for flexural strength measurement. After 24 hours, the specimens were demolded and cured in a climate chamber with a controlled temperature and humidity of $21^{\circ} \mathrm{C}$ and $95 \%$, respectively.

The foamed concrete was produced in three steps. Firstly, cement slurry was produced by mixing cement, silica fume, fine quartz sand, water, superplasticizer and stabilizer using a high intensity mixer (Eirich mixer) to prevent 
agglomeration of fine materials. The second steps was that of producing the foam using a foam generator (SG S9, Sika Germany). The dosage of the foaming agent was $2 \%$ with the water pressure applied being 3 bar. The density of preformed foam is $35 \mathrm{~kg} / \mathrm{m}^{3}$. The final step was the mixing of the foam generated with the cement slurry, with these materials being mixed until the specific homogeneity was achieved. Fresh properties, including a flow table test and the density of the fresh concrete, were also examined according to European standards (EN 206-1 [10] and EN 12350-6 [36]). The same molds as used for the LWAC specimens were also used for the foamed concrete specimens, with the specimens also being cured under the same condition.

\section{Material characterization}

Image-based characterization methods, scanning electron microscopy and X-ray micro-computed tomography, were adopted to investigate the microstructures of the LWAC and foamed concrete. In addition, sensitive experimental tools were used to measure the compressive and flexural strength and thermal conductivity of the LWC specimens.

\subsection{SEM}

Scanning electron microscopy (SEM) is a method used mainly for investigating the surfaces of materials at a high magnification. This instrument has been used widely to investigate the microstructures of cementitious materials [37, 38]. To obtain a high-resolution SEM image in the analysis of the solid and pore structures of the LWC specimens, a field emission gun was utilized. Secondary electron (SE) images at different magnifications were used to investigate the micro structures of the specimens. Samples for the SEM investigations were selected from the inner part of the cubic specimens and were coated with gold to obtain a sufficient conductivity for the measurement.

\section{$3.2 \mu-\mathbf{C T}$}

$\mathrm{X}$-ray micro-computed tomography $(\mu$-CT) is a noninvasive and nondestructive method for visualizing the inner structures of materials and has been utilized to examine the 3D geometric properties of various solid materials. $\mu$-CT images have been used to investigate the pore and solid structures of concrete in the past $[20,39,40]$. Compared with SEM, $\mu$-CT has the advantage of enabling internal analysis of a specimen in 3D without damaging it.

Fig. 2 shows an image process segmenting the pore and solid phases of the specimens for more effective analysis of material characteristics. Each two-dimensional (2D) image in this figure was composed of $1000 \times 1000$ pixels with a $29.7 \mu \mathrm{m}$ pixel size. For the foamed concrete analysis, image segmentation of pores and solid phase elements were needed for the original image. In this investigation, image contrast was adjusted for more effective pore segmentation 


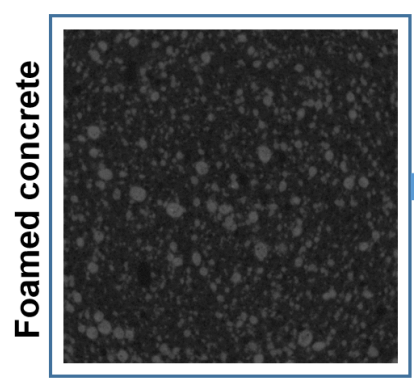

$\mu-C T$ in 2D

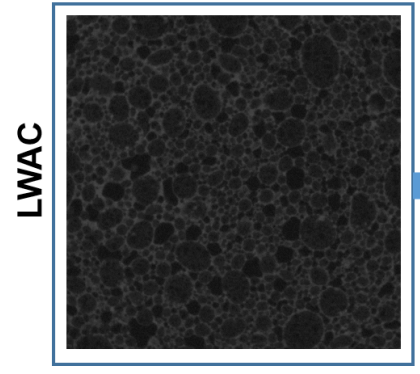

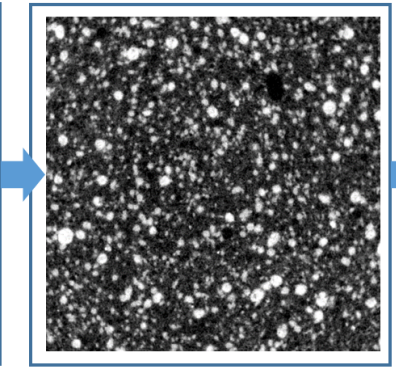

adjusted $\mu-C T$

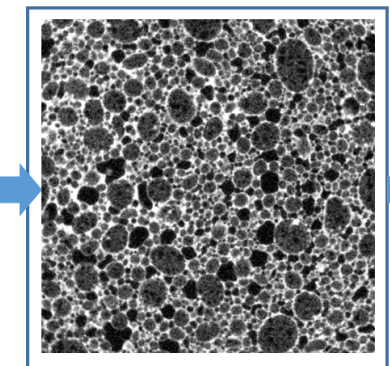

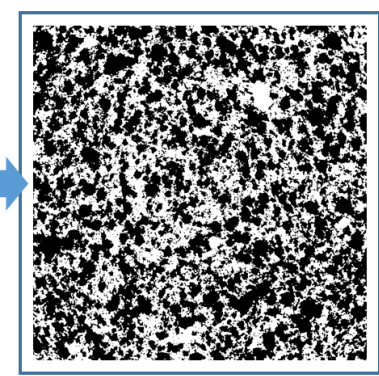

Binary image (pore)

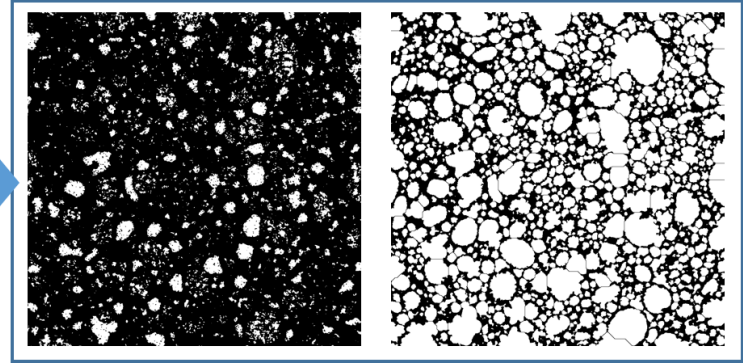

Figure 2: $\mu$-CT imaging of foamed concrete and LWAC (Note: the $1^{\text {st }}$ figures in each material are 8-bit CT images, while the $2^{\text {nd }}$ figures have been adjusted to enhance the contrast. The other images are the segmented images of pores and aggregates. In the binary pore image $\left(3^{r d}\right)$, the white represents pores, while the black represents the background. The white region in the aggregate binary image ( $4^{\text {th }}$ in LWAC) represents aggregate solids.)

by manipulating the gray-scale histogram intensity, as shown in the $2^{\text {nd }}$ graph in Fig. 2. A binary image was then generated by specifying the threshold. To select the threshold value, manual and Otsu [41] thresholding methods were used, with the image toolbox in MATLAB (R2018a) also being used for image conversion. In the binary image of the foamed concrete sample, white represents the pores, while black represents the solid phase.

For LWAC, a more complex segmentation procedure is required because the material contains lightweight aggregates. In general, lightweight aggregates are composed of numerous pores inside solid particles, with lightweight particles having less rigid solid structures than the matrix solid. In the adjusted LWAC image (Fig. 2), pores are described in black, while other solids are presented in gray values according to their relative densities. For example, the solids of the lightweight aggregates are described in dark gray, while the cement matrix is presented in light gray; this indicates that the matrix is denser than the solids of the lightweight aggregates. LWAC image processing for classifying pores, aggregates and the matrix was performed using a multi-level thresholding method [42], with a modified watershed algorithm being additionally conducted to segment each aggregate and pore. For both the FC and LWAC, three-dimensional (3D) images were obtained by stacking the binarized 2D images. 


\subsection{Property evaluations}

Material properties such as dry density, compressive and flexural strengths, and the thermal conductivity of the LWC specimens were measured using proper experimental approaches, which satisfy European standards. The dry density values of the specimens were measured at an age of 28 days after oven drying at $105^{\circ} \mathrm{C}$ to achieve a constant mass, according to EN 12390-7 [43]. To measure the compressive and flexural strengths of the specimens, Toni Technik (Zwick Roell, Germany) digital modern crushing machines, were used according to EN 12390-4 [44] and EN 123905 [45], respectively. The thermal conductivity of the LWC specimens was evaluated using a Hot Disk transient plane source method according to ISO 22007-2 [46]; this systematic tool is composed of the two main parts, the Hot Disk main device and a sensor. For the measurement, the sensor is positioned between two identical samples of the target material and works as a current supplier and a temperature detector simultaneously. From the change of temperature during the measurement period, the thermal properties can be computed [47, 48]. Because of its high sensitivity to the moisture content of the material, the measurement conditions are very important with the Hot Disk. The specimens therefore were oven dried and cooled to room temperature under zero humidity conditions for the measurement. Here, cubic specimens with $40 \mathrm{~mm}$ edge length were used for the measurements. For the compressive and flexural strength, as well as thermal conductivity tests, five measurements from each case were performed to increase accuracy, with the mean values being presented in this paper.

\section{Results and discussions}

The pore and solid characteristics of the LWC specimens were investigated using SEM images. In addition, detailed pore characteristics of LWC specimens with the same density level were examined using $\mu$-CT images. The compressive and flexural strengths as well as thermal conductivity of the LWC specimens are presented, and the correlation between the material characteristics and properties is described. The lightweight aggregate concrete specimens are denoted as LWAC with the density level, while FC denotes the foamed concrete specimens.

\subsection{Microstructures of the LWC specimens}

\subsubsection{SEM investigation}

A general overview of the LWC microstructures was undertaken using SEM as shown in Figs. 3 and 4. These figures show the SEM images of the LWAC and FC specimens. In Fig. 3, the pore and solid structures of the LWAC specimens have been presented. The left image of Fig. 3(a) shows the lightweight concrete specimens with lightweight aggregates. 

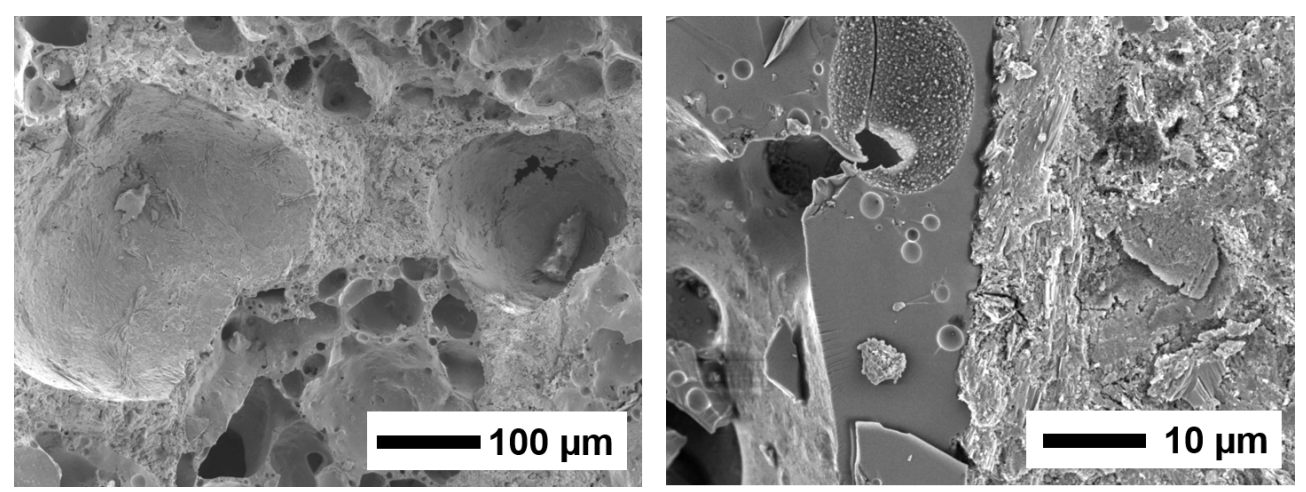

(a)
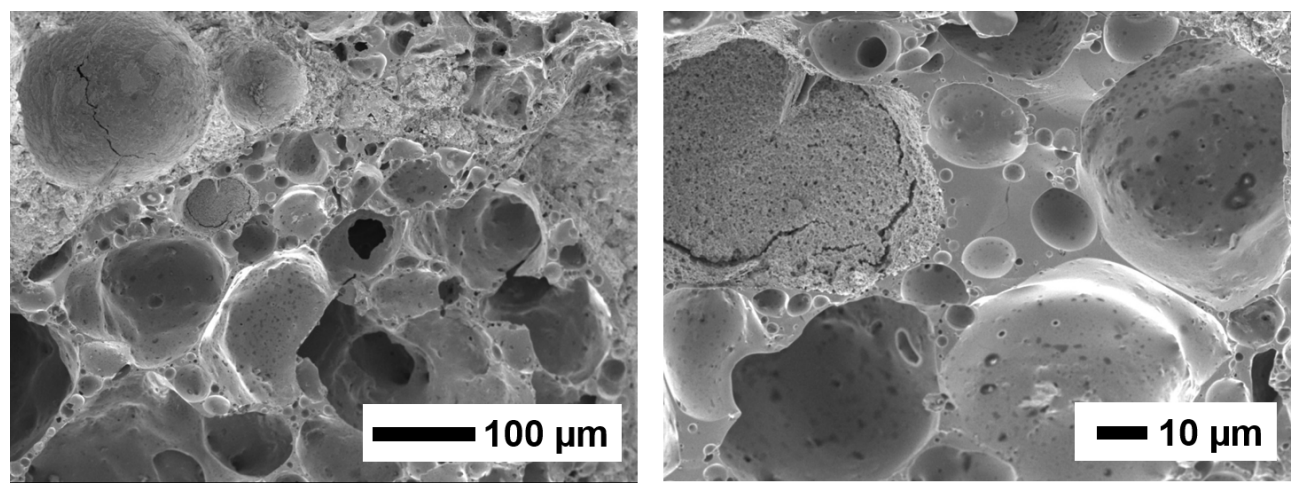

(b)
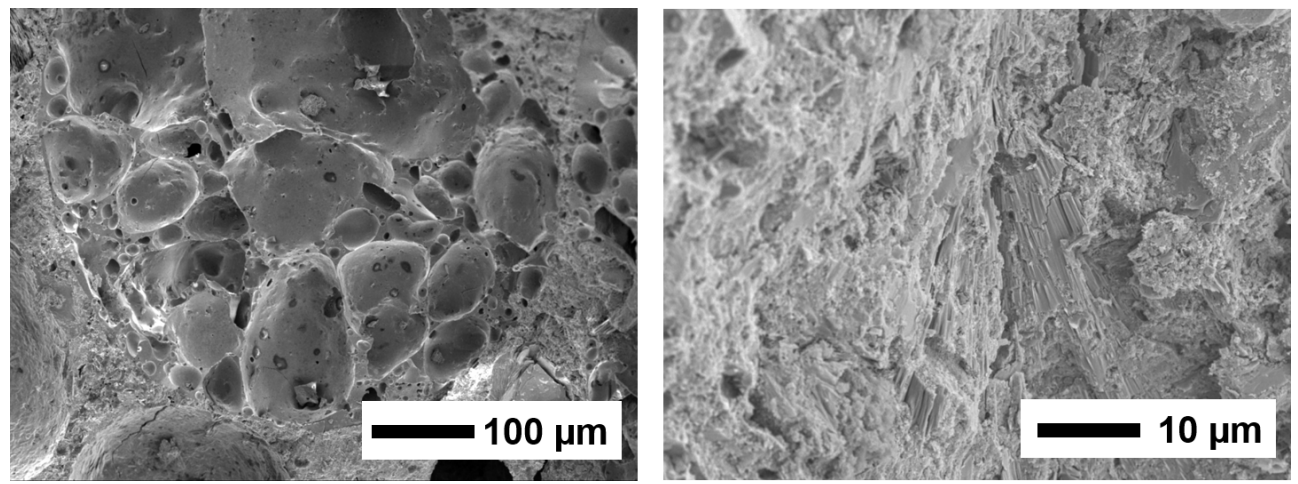

(c)

Figure 3: SEM images of the pore and solid structures of lightweight aggregate concrete (LWAC) specimens: (a) LWAC500, (b) LWAC750, (c) LWAC1000 

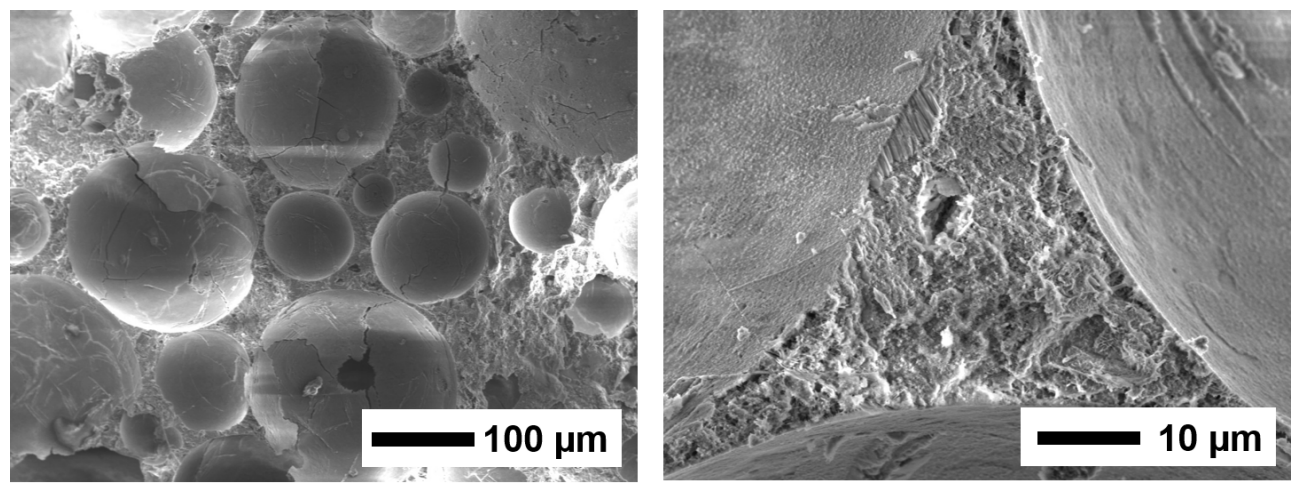

(a)
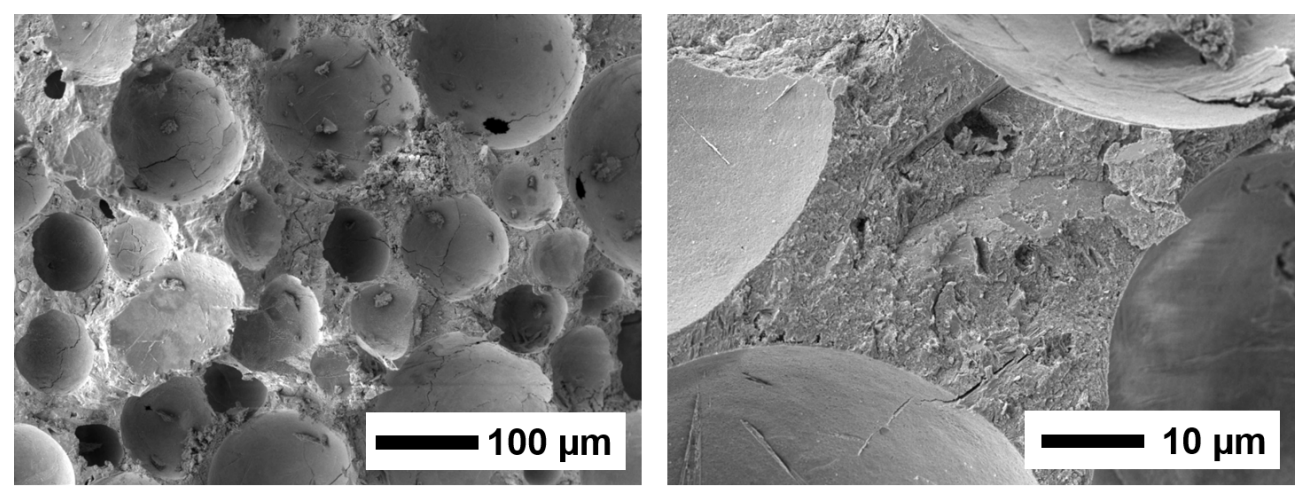

(b)
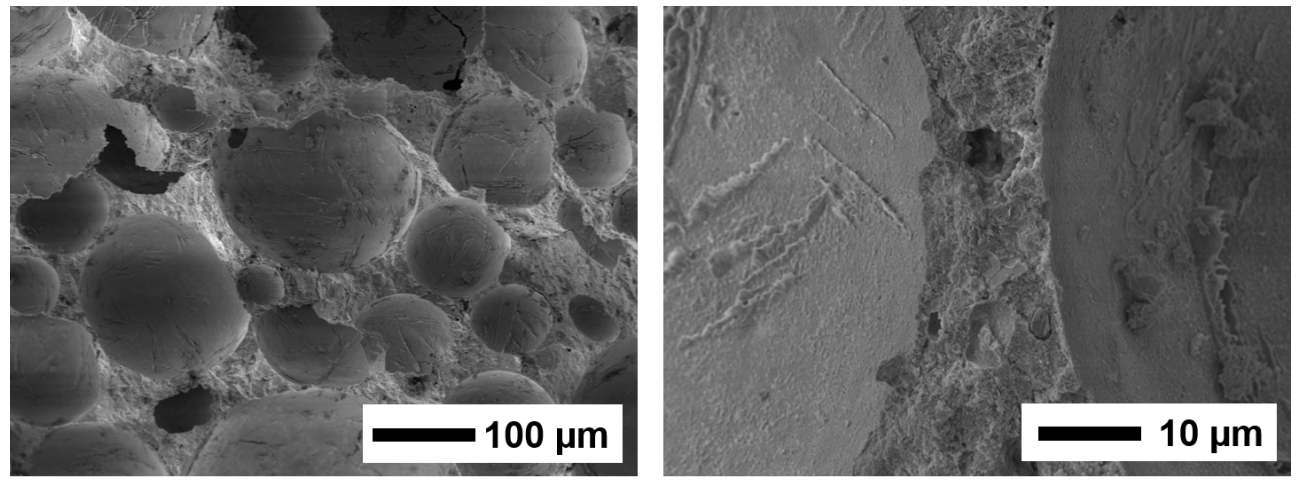

(c)

Figure 4: SEM images of the pore and solid structures of foamed concrete (FC) specimens: (a) FC500, (b) FC750, (c) FC1000 
In this image, only two pores are visible in the cement matrix with the sizes being between 200 and $400 \mu \mathrm{m}$; the other pores belong to the lightweight aggregates, which are smaller than $50 \mu \mathrm{m}$, in general. In the right image of the LWAC500 specimen, a connection between the aggregate (left part of the image) and the cement matrix (right part) can be identified. The lightweight aggregate shows a typical glassy structure, while the cement matrix is not very dense; in the cement matrix, portlandites, which are sheet forms, are clearly visible, with numerous micro-pores also visible. Similarly to the LWAC500 specimen, most of the pores of the LWAC750 specimen are in the cement matrix, being less than $200 \mu \mathrm{m}$, while the pore sizes of the aggregates are in the range 20-100 $\mu \mathrm{m}$ (Fig. 3(b)). In the LWAC1000 specimen, the pores in the aggregates are much more dominant than in the other LWAC specimens because the cement matrix portion, which is less porous than in the lightweight aggregates, is larger than in the other cases. In the closer view of the cement matrix at the right of Fig. 3(c), a dense solid structure with the typical formation of portlandite is visible. From these SEM images, it can be seen that in each specimen most of the pores exist in the lightweight aggregates, with less pores in the cement matrix.

The microstructural characteristics of the FC specimens are presented in Fig. 4. Like the LWAC specimens, the general pore and solid structures of the FC specimens can be examined using SEM images. The left images of each specimen present the pore structure, while the right images show the magnified solid structures. In Fig. 4(a), a general pore size distribution can be identified (left), with the range of pore sizes being between 30 and $200 \mu \mathrm{m}$. In the right figure, the cement matrix in the closer view seems relatively denser than that of the LWAC, with some single phases, such as ettringite (needle shape) and C-S-H (sponge form) being visible. The pore sizes of FC750 in Fig. 4(b) are almost the same as those of FC $500(40-200 \mu \mathrm{m})$, but the cementitious walls between the pores are mostly thicker in the FC750 specimen. Furthermore, the cement matrix is particularly much denser in the FC750 specimen, with the single phases not clearly visible in the high-magnification image in Fig. 4(b). The pore sizes of the FC1000 specimen are almost the same as those of the other densities, and a closer look shows that the solid phase is similar to that of the FC750 specimen.

As shown in Figs. 3 and 4, the general microstructures of LWAC and FC specimens can be effectively examined from the SEM data with very high magnifications. However, these images can only provide 2D information regarding a specific surface, and it is thus difficult to identify the overall microstructural characteristics. Additional investigation is therefore needed for a more detailed microstructural investigation.

\subsection{2 $\mu$-CT analysis}

In order to overcome the limitation of SEM, $\mu$-CT examination was conducted to complement the microstructural investigation. Fig. 5 shows the 8 -bit 3D $\mu$-CT images of the LWC specimens. Each image is composed of $1000 \times 1000 \times 1000$ 


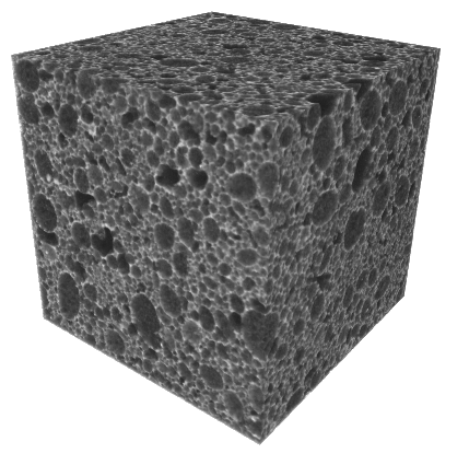

(a)

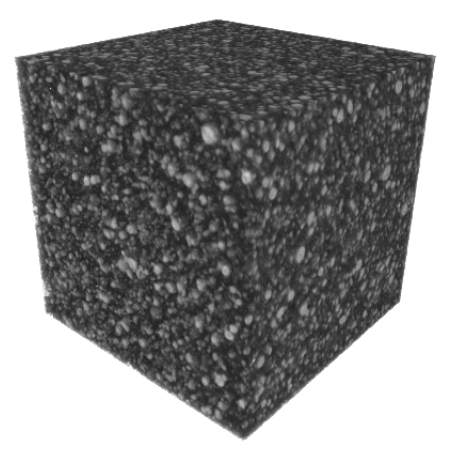

(d)

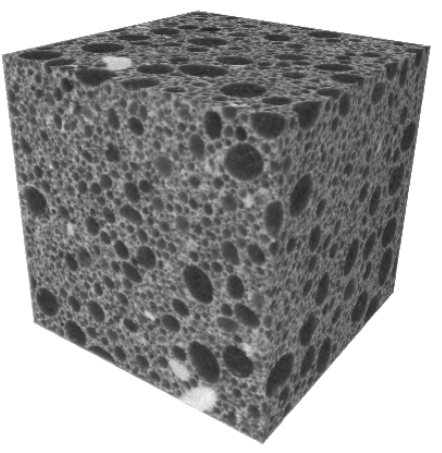

(b)

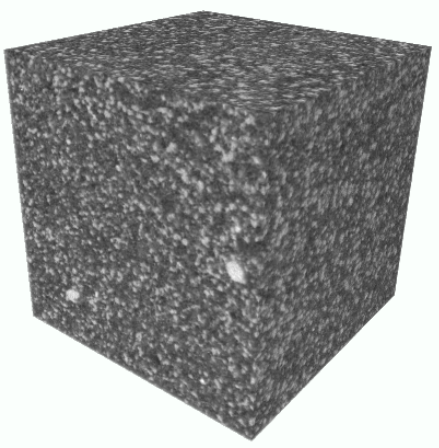

(e)

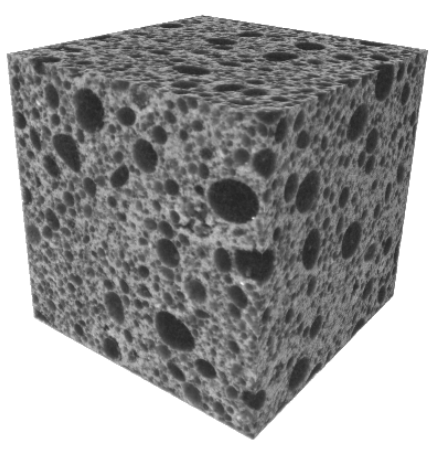

(c)

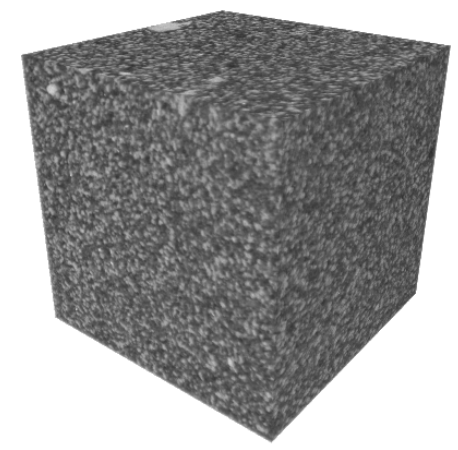

(f)

Figure 5: $\mu$-CT microstructures of the LWC specimens in 3D: (a) LWAC500, (b) LWAC750, (c) LWAC1000, (d) FC500, (e) FC750, (f) FC1000 


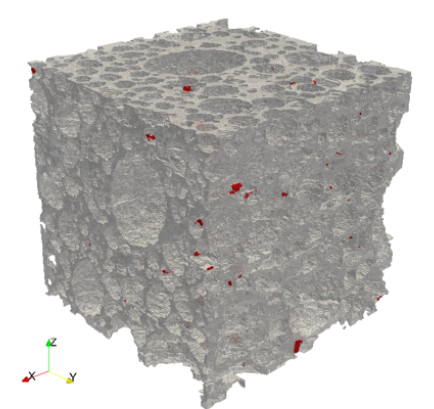

LWAC500 (matrix)

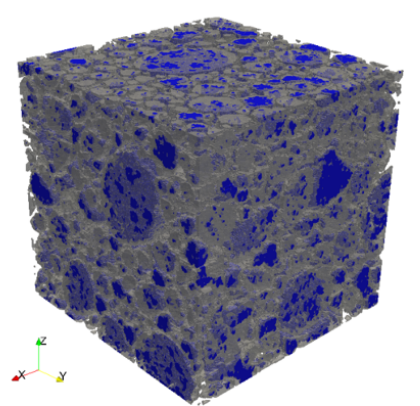

LWAC500 (aggregates)

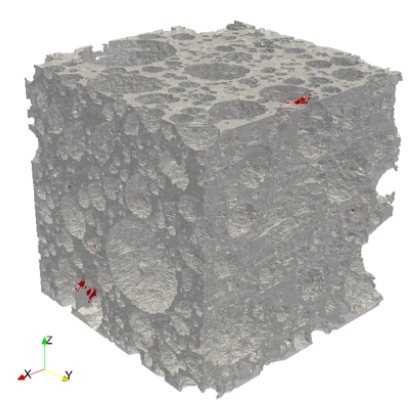

LWAC750 (matrix)

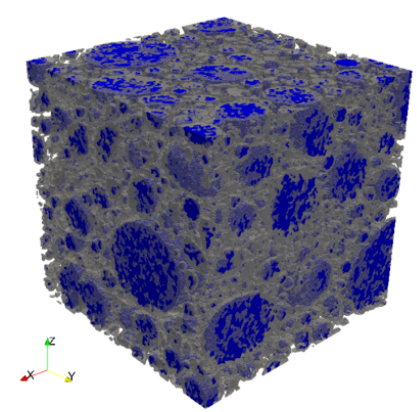

LWAC750 (aggregates)

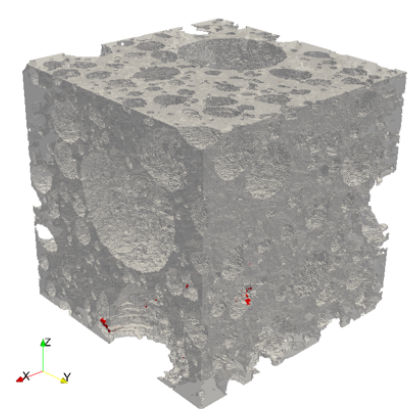

LWAC1000 (matrix)

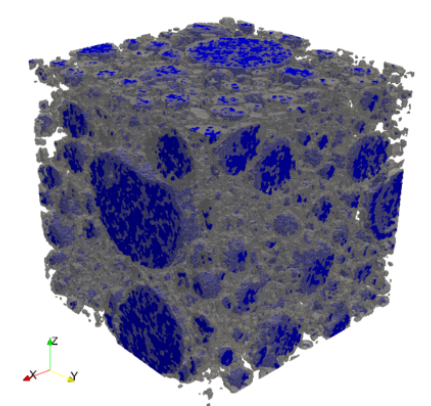

LWAC1000 (aggregates)

Figure 6: Pore structures of the LWAC specimens (Note: in each specimen, the top figures show the pores within the matrix (red), while the bottom figures show the pores inside the lightweight aggregates (blue).)

voxels with a $29.7 \mu \mathrm{m}$ voxel size, with each voxel described with a value between 0 (black) and 255 (white) according to the relative density of the compounds. For example, voxels described in black or dark gray denote components with pores (black) or low density constituents (dark gray), while the other voxels in light gray are more dense solid structures. From the $\mu$-CT images in Fig. 5, an overview of the 3D microstructures of the specimens can be identified. In this figure, the overall color of the gray-scale in each specimen becomes brighter as the density of the specimen increases from 500 to 1000 for both the LWAC (Figs. 5(a)-(c)) and FC (Figs. 5(d)-(f)) specimens. In particular, in the LWAC specimens in Figs. 5(a)-(c), the regions in relatively dark gray are the lightweight aggregates, while the brighter parts are the cement matrix. In these figures, the lightweight aggregates in dark gray are the same, but the binder part of the specimen with a larger density is brighter than that of the specimens with a lower density; this denotes that the cement matrix becomes denser with specimen density. In the FC specimens, it is also noticeable that the color of the solid phase in each specimen becomes brighter with average density, and the heterogeneity of the matrix decreases in specimens with larger densities. 


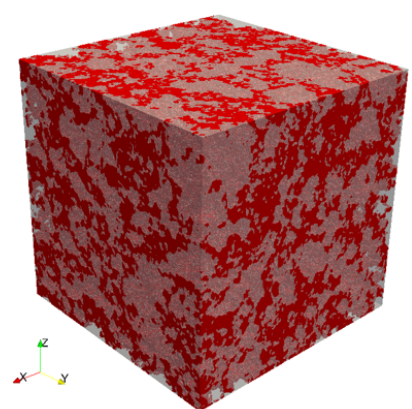

FC500

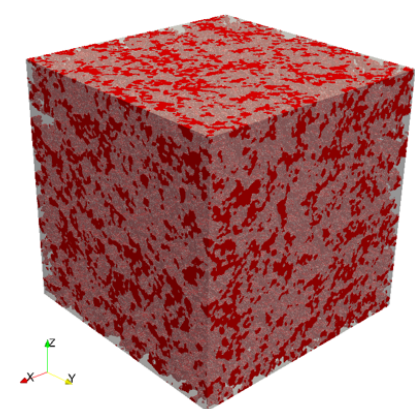

FC750

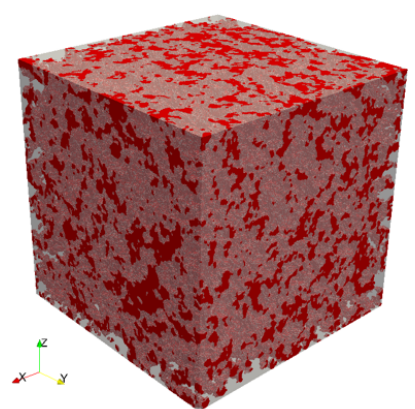

FC1000

Figure 7: Pore structures of the FC specimens (Note: the red in each figure shows the pores within the matrix.)

For further investigation of the microstructures, the pore characteristics of the specimens were also evaluated using the $\mu$-CT images. Pore characteristics such as porosity and pore structure are critical for the physical properties of concrete, and a detailed investigation of the pore microstructure is needed for a better understanding of lightweight concrete. Figs. 6 and 7 present the pore structures of the LWC specimens. In the $\mu$-CT image segmentation, a region of interest (ROI) for each case was selected from the specimen in Fig. 5 for efficiency of image processing; subdomains were selected by considering the porosity of the whole domain and are composed of $400 \times 400 \times 400$ voxels.

Fig. 6 shows the pore structures of the LWAC specimens. Here, the pore structures were classified into two categories: pores within the binder (red) and pores inside the lightweight aggregates (blue). The lightweight aggregate is a much more highly porous material than the binder, with more than $50 \%$ of the volume being composed of the lightweight aggregates in each LWAC specimen. As confirmed in Fig. 6, the pores in the lightweight aggregates dominate in determining the porosity of the LWAC specimen. The LWAC specimen contains less lightweight aggregates as the density of the specimen increases, and therefore, the LWAC500 specimen has the most lightweight aggregates and pores inside the aggregates compared to the other specimens. In contrast, the FC specimens have no aggregates larger than $0.3 \mathrm{~mm}$, with all the pores being in the matrix (binder), as shown in Fig. 7. In this figure, more and larger pores are distributed in the FC500 specimen than in the other specimens, with the results demonstrating that porosity and the size of pore clusters tend to increase as the density of foamed concrete decreases.

For a more detailed investigation of pore size, pore size distributions of the specimens were also evaluated, as shown in Fig. 8. In this figure, a clear difference between the pore size characteristics of the LWAC and FC specimens can be identified. In Fig. 8(a), the frequency of the size distribution decreases as the pore size increases, denoting that the LWAC specimens contain numerous small pores. Alternatively, the peak frequency of the pore size distribution for the FC specimens are in the range of 150-200 $\mu \mathrm{m}$ (Fig. 8(b)). In this figure, the total volume of pores less than $60 \mu \mathrm{m}$ is similar in all FC specimens, but the proportion of pores larger than $80 \mu \mathrm{m}$ increases as the specimen density 


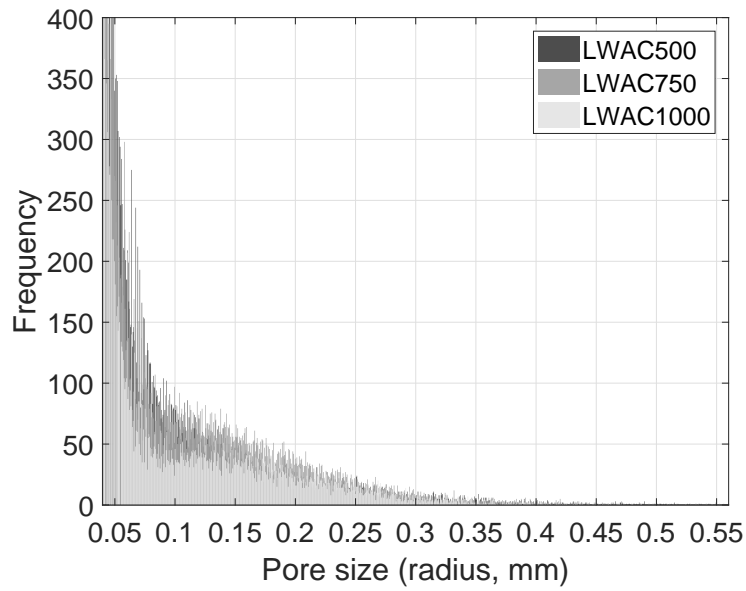

(a)

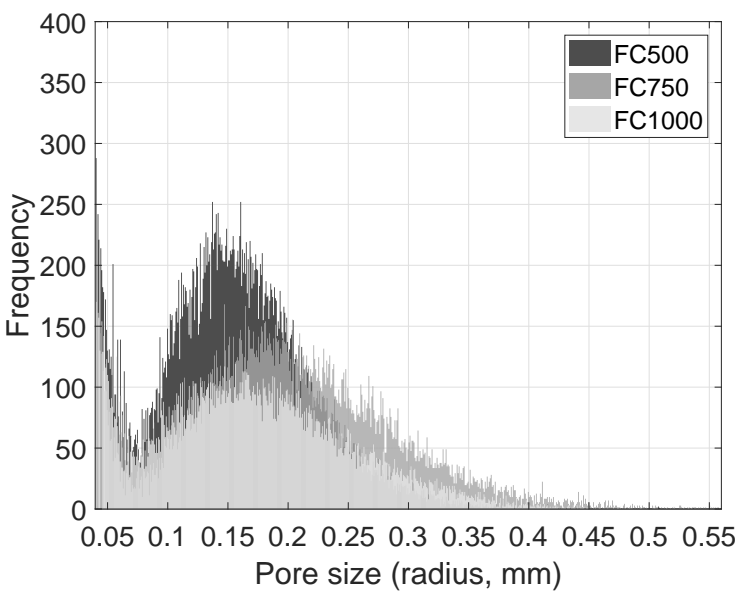

(b)

Figure 8: Pore size distribution of LWC specimens: (a) LWAC specimens, (b) FC specimens

decreases. The results in this figure prove that the pore size distribution trend differs according to the type of LWC; the pores in the LWAC being composed of relatively small pores, with the FC specimens containing large air voids that can affect the mechanical properties of the materials.

Quantitative porosities of the LWC specimens are presented in Fig. 9. These values were computed on the basis of the 3D $\mu$-CT images. Since the pixel size in this study was $29.7 \mu \mathrm{m}$, only pores larger than $29.7 \mu \mathrm{m}$ were taken into consideration in calculating specimens' porosity. The issue related to the $\mu$-CT resolution has been discussed in $[49,50,51]$. In Fig. 9, capillary pores less than the pixel size were not taken into account; these pores can be detected using other methods, e.g., mercury intrusion porosimetry (MIP). Although the capillary pores can contribute to the shrinkage of concrete, it is well known that pores larger than the capillary pore size are more significant to determine the material strength and thermal conductivity. In addition, the MIP test has the advantage of detecting very tiny pores while this method is hard to detect the spatial distribution of pores. Therefore, the effect of pores larger than the resolution of the $\mu$-CT images is only considered here, and complementary investigation with other characterization tools can be done as further study.

As was discussed in relation to the pore structure images and shown in Fig. 9, the porosity of the LWAC specimens was strongly dependent on the fraction of pores in the lightweight aggregates, with binder porosities being almost the same regardless of density. This result describes that the pore structure of lightweight aggregate concrete is mainly affected by the pore characteristics of lightweight aggregates. The porosity of the FC specimens was fully determined by the pore structures of the binder. The porosity of both the LWAC and FC specimens decreased as the density of the specimens increased. Though the FC specimens contained no porous lightweight aggregates, the porosity of the FC 


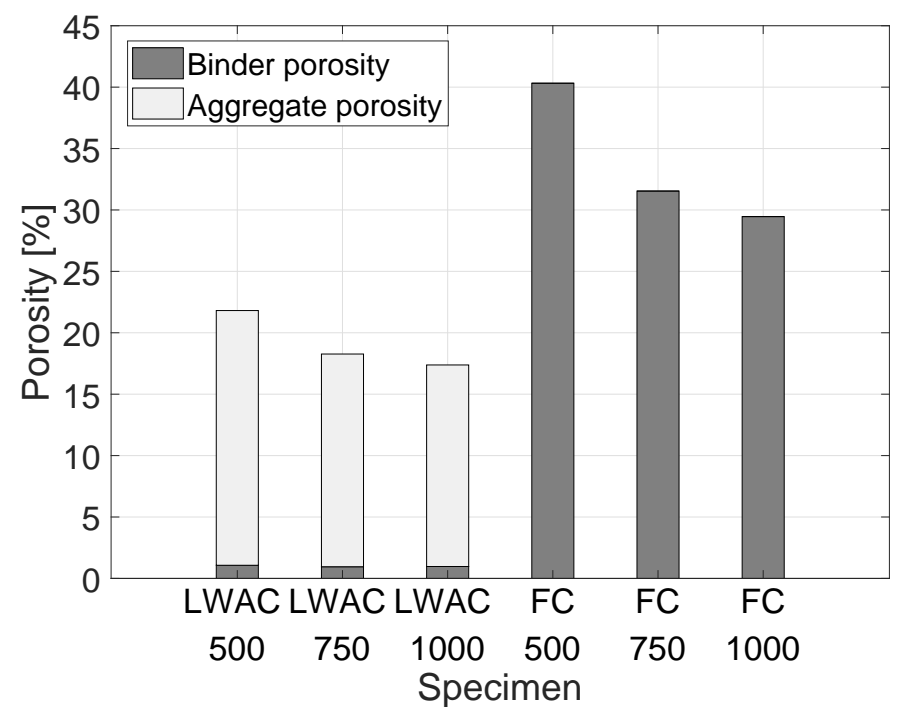

Figure 9: Porosity of the LWC specimens

Table 4: Fresh density of LWC specimens

\begin{tabular}{|c||c|c|c|c|c|c|}
\hline Specimen & LWAC500 & LWAC750 & LWAC1000 & FC500 & FC750 & FC1000 \\
\hline $\begin{array}{c}\text { Fresh density } \\
{\left[\mathbf{k g} / \mathbf{m}^{3}\right]}\end{array}$ & 630 & 880 & 1100 & 620 & 900 & 1080 \\
\hline
\end{tabular}

specimen was about twice that of the LWAC specimen with the same density level because of the use of the foaming agent. The results confirm that foamed concrete has a much larger porosity than lightweight aggregate concrete, when the density of the materials is almost the same. The effects of the pore characteristics of both LWC specimens on material properties will be discussed in the following section.

\subsection{Material properties of the LWC specimens}

\subsubsection{Specimen density}

The target density classes in this study were 500,750 , and $1000 \mathrm{~kg} / \mathrm{m}^{3}$ for both the LWAC and FC specimens, with the LWC specimens being produced according to the mix compositions in Table 3. Fresh density test results are presented in Table 4. They clearly confirm that the fresh density of foamed concrete was similar to that of lightweight aggregate concrete at all density classes. Fig. 10 presents the average dry densities of the LWC specimens. Although there were some differences between the target and measured dry densities, the results obtained are in reasonable agreement with the target density in each class. In this figure, the material density of the LWAC and FC specimens with the same density level are similar, with the porosity being significantly different (Fig. 9). The density of FC750, for instance, 


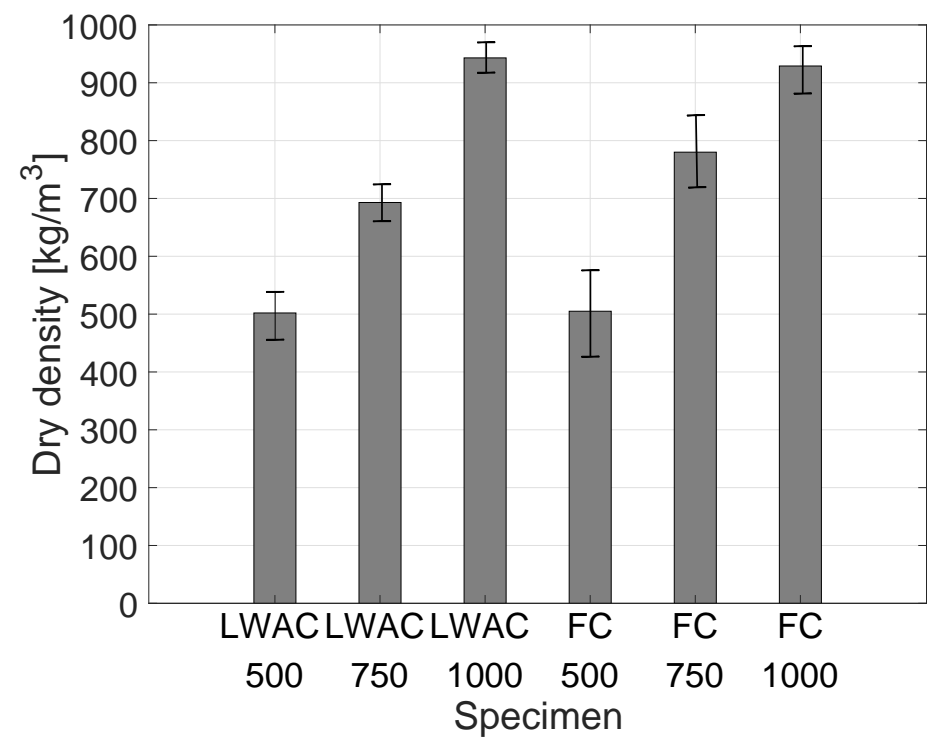

Figure 10: Dry density of LWC specimens

was higher than that of LWAC750, with the porosity of the foamed concrete being almost double; this indicates that the solid structures of the FC specimens were much denser than those of the LWAC specimens, as was also found via SEM analysis.

\subsubsection{Thermal conductivity}

One of the main advantages of lightweight concrete is its reduced thermal conductivity in terms of energy efficiency. Therefore, it is important to produce lightweight concrete with lower thermal conductivity, insofar as materials with better thermal insulation are desired. Fig. 11 shows the thermal conductivity results of the LWC specimens measured using the Hot Disk transient sensor method. According to this figure, all the specimens produced in this study had a thermal conductivity below $0.35 \mathrm{~W} /(\mathrm{m} \cdot \mathrm{K})$, meaning that they can be considered as good insulation materials compared to conventional concrete [15]. The thermal conductivity of the LWC specimens increased with material density for both the LWAC and FC specimens. The thermal conductivity of specimens with the same density level was almost the same, with the tendency being similar to that of the density values in Fig. 10. The results support the contention that the thermal conductivity of LWC specimens is strongly dependent on material density, regardless of the type of lightweight concrete used. 


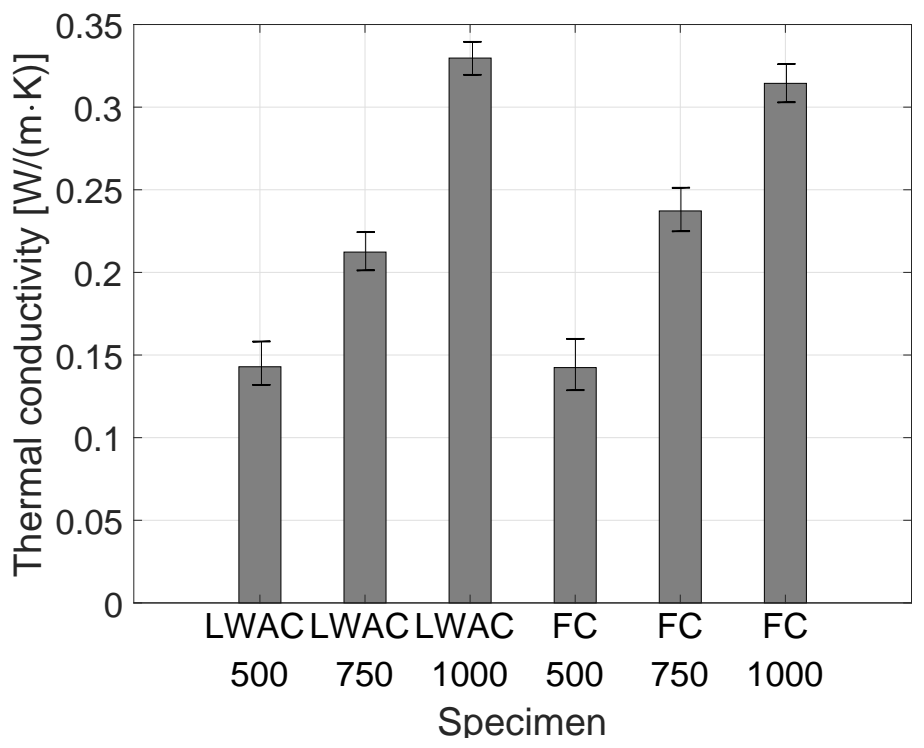

Figure 11: Thermal conductivity of LWC specimens

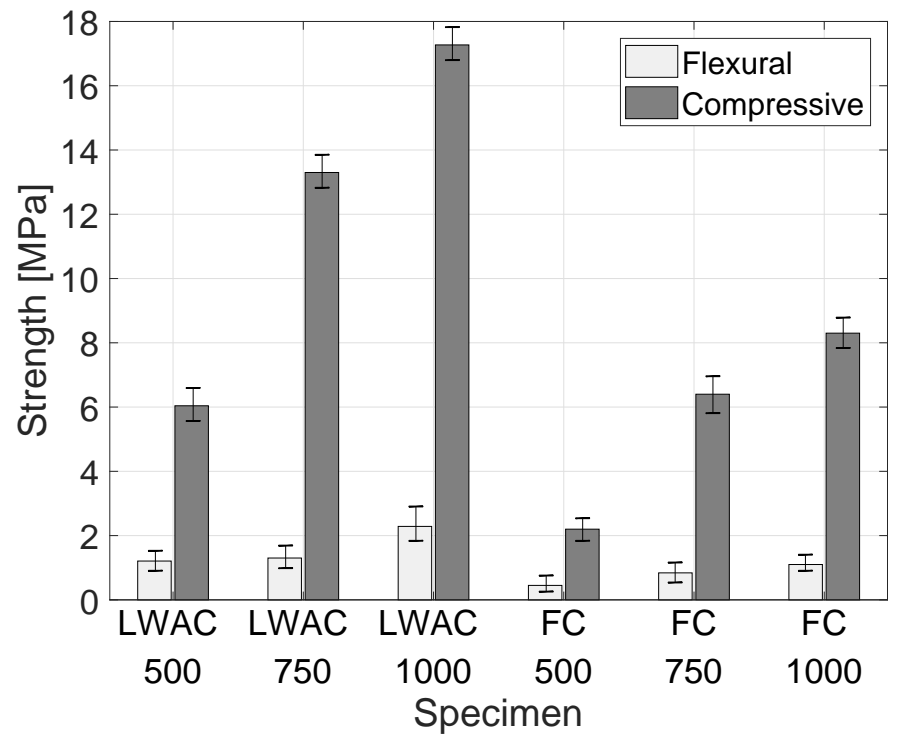

Figure 12: Compressive and flexural strength of LWC specimens 


\subsubsection{Strength}

The other properties evaluated in this study were compressive and flexural strengths, shown in Fig. 12. Even though lightweight concrete is not generally used as a major component of structures, there are minimum requirements regarding its mechanical properties, when it is to be used as a part of structures, with compressive strength being an important property regulating concrete quality. According to Fig. 12, both the flexural and compressive strength values increased; with the density of the specimens, in regard to both the LWAC and FC specimens. The flexural and compressive strengths of the LWAC and FC specimens, with the same density level showed significant differences in distinction to the thermal conductivity trends; the strength values of the LWAC specimens were much higher than those of the FC specimens. In particular, the compressive strength values of the LWAC specimens were more than double those of the FC specimens at each density level. Considering the material characteristics evaluated, the strength trends were found to be related to the porosity and pore size distribution of the material. Regarding porosity (Fig. 9), the FC specimen contained more pores within the specimen than the LWAC specimen when the material density was similar, with the strength result showing a trend opposite to that of the porosity result: material with large porosity showed lower strength. In addition, the pore size distribution showed that the FC specimens had more large pores than the LWAC specimens with the same densities; it is known that large pores affect the mechanical properties of materials, with small pores having a less significant influence on material strength.

As demonstrated by the $\mu$-CT investigations, material density was almost the same but the porosity and the proportion of large pores was much higher in the FC specimens, indicating that the solid structure of the matrix was relatively denser in the FC specimens. In the SEM images of the LWAC specimens, it was confirmed that the microstructure of the matrix was not as dense as that of the FC specimen, but that the solid structure of the lightweight aggregate had the typical glassy characteristics, which means that it can be considered to be a substantial solid, even though the aggregate was a highly porous material. This result denotes that the mechanical properties of the LWAC specimens were strongly affected by the characteristics of the lightweight aggregates and that the use of lightweight aggregates with dense solid structures can contribute to achieving a higher strength than that of foamed concrete with similar densities. Moreover, the results suggest that the use of properly designed lightweight aggregate concrete is more advantageous than the use of foamed concrete in terms of mechanical properties without the loss of insulation capabilities.

\section{Conclusions}

The above investigation of the characteristics and properties of lightweight aggregate concrete and foamed concrete with the same density levels was discussed based on image analysis. For effective comparison, the target material 
densities of each concrete type were fixed at 500,750 , and $1000 \mathrm{~kg} / \mathrm{m}^{3}$, with the specimens produced according to the proper mix compositions. To investigate the microstructural characteristics of the specimens, the image-based methods of SEM and $\mu$-CT scanning were performed, and the microstructures of the lightweight concrete specimens were characterized for both solid and pore phases. Thermal and mechanical properties including density were also measured using standardized methods, with their relationship to material characteristics being discussed.

The SEM images showed the microstructural features of the specimens, and it was confirmed that the solid structures of the matrix in foamed concrete are relatively denser than that of lightweight aggregate concrete. Furthermore, it was found that aggregate particles contain the typical glassy solids which can contribute to material strength. Using $\mu$-CT images, general pore structures were visualized in $3 \mathrm{D}$, and the porosity information of each compound in the specimens was identified. The porosity of both types of lightweight concrete decreases as the density of the material increases. In particular, the porosity of the lightweight aggregate concrete is strongly affected by the pore characteristics of the lightweight aggregates, while that of the foamed concrete is totally dependent on the pore structure of the matrix. The results obtained also demonstrated that foamed concrete has larger porosity than lightweight aggregate concrete when the material density is similar.

The thermal conductivity and the strength of the specimens tended to increase with material density. The tendency of thermal conductivity showed a close relationship to material density, while compressive and flexural strengths were more influenced by porosity and pore size distribution than density because of the solid characteristics of each type of concrete. Moreover, when the density level of the material was within the same range, the lightweight aggregate concrete showed higher strength than the foamed concrete although their thermal conductivity was almost the same. The results suggest that the proper use of lightweight aggregate concrete can be more beneficial in terms of having a material with better mechanical performance by minimizing the loss of the insulation effect. In addition to this study, further case studies and microstructural investigations such as XRD should be undertaken in order to increase the reliability of the results obtained herein.

\section{Acknowledgements}

The project is supported by the German Federal Ministry of Education and Research (BMBF, Project Number: 13XP5010B and 01DR16007). This work is also supported by Basic Science Research Program through the National Research Foundation of Korea (NRF) funded by the Ministry of Education (2016R1A6A3A03007804, NRF2015K1A3A1A59073929, and NRF-2016R1D1A1B03931635 ). In addition, the authors want to thank Dr. Paul H. Kamm (Helmholtz Centre Berlin) for his assistance in X-ray $\mu$-CT imaging. 


\section{References}

[1] A. M. Neville, Properties of concrete, Wiley, Chichester, 2012.

[2] B. Vakhshouri, S. Nejadi, Mix design of light-weight self-compacting concrete, Case Studies in Construction Materials 4 (2016) 1-14.

[3] S. Mindess, J. F. Young, D. Darwin, Concrete, 2nd Ed., Prentice Hall, New York, 2002.

[4] P. K. Mehta, P. J. M. Monteiro, Concrete: microstructure, properties and materials, 4th Ed., McGraw-Hill, New York, 2015.

[5] S.-Y. Chung, T.-S. Han, S.-Y. Kim, Reconstruction and evaluation of the air permeability of a cement paste specimen with a void distribution gradient using CT images and numerical methods, Construction and Building Materials 87 (2015) 45-53.

[6] H. J. H. Brouwers, H. J. Radix, Self compacting concrete: theoretical and experimental study, Cement and Concrete Research 35 (2005) 2116-2136.

[7] M. E. Dilli, H. N. Atahan, C. Sengul, A comparison of strength and elastic properties between conventional and lightweight structural concretes designed with expanded clay aggregates, Construction and Building Materials 101 (2015) 260-267.

[8] S.-Y. Chung, T.-S. Han, S.-Y. Kim, J.-H. J. Kim, K. S. Youm, J.-H. Lim, Evaluation of effect of glass beads on thermal conductivity of insulating concrete using micro CT images and probability functions, Cement and Concrete Composites 65 (2016) 150-162.

[9] F. Roberz, R. C. G. M. Loonen, P. Hoes, J. L. M. Hensen, Ultra-lightweight concrete: Energy and comfort performance evaluation in relation to buildings with low and high thermal mass, Energy and Buildings 138 (2017) 432-442.

[10] EN 206-1, Concrete - Part 1: Specification, performance, production and conformity (Aug. 2000).

[11] P. Sikora, A. Augustyniak, K. Cendrowski, E. Horszczaruk, T. Rucinska, P. Nawrotek, E. Mijowska, Characterization of mechanical and bactericidal properties of cement mortars containing waste glass aggregate and nanomaterials, Materials 9 (2016) 701.

[12] R. Yu, D. V. van Onna, P. Spiesz, Q. L. Yu, H. J. H. Brouwers, Development of ultra-lightweight fibre reinforced concrete applying expanded waste glass, Journal of Cleaner Production 112 (2016) 690-701. 
[13] S.-Y. Chung, T.-S. Han, T. S. Yun, K. S. Yeom, Evaluation of the anisotropy of the void distribution and the stiffness of lightweight aggregates using CT imaging, Construction and Building Materials 48 (2013) 998-1008.

[14] M. R. Jones, Foamed concrete for structural use. In: Proceeding of one day seminar on foamed concrete: properties, applications and latest technological developments, Loughborough University, 2001.

[15] K. Ramamurthy, E. K. K. Nambiar, G. I. S. Ranjani, A classification of studies on properties of foam concrete, Cement and Concrete Composites 31 (2009) 388-396.

[16] S.-Y. Chung, C. Lehmann, M. A. Elrahman, D. Stephan, Pore characteristics and their effects on the material properties of foamed concrete evaluated using micro-ct images and numerical approaches, Applied Sciences 7 (2017) 550:1-19.

[17] C. Muoz-Ruiperez, A. Rodrguez, S. Gutirrez-Gonzlez, V. Caldern, Lightweight masonry mortars made with expanded clay and recycled aggregates, Construction and Building Materials 118 (2016) 139-145.

[18] H. Cui, T. Lo, S. Memon, F. Xing, S. X, Effect of lightweight aggregates on the mechanical properties and brittleness of lightweight aggregate concrete, Construction and Building Materials 35 (2012) 149-158.

[19] S.-Y. Chung, M. A. Elrahman, D. Stephan, Effect of different gradings of lightweight aggregates on the properties of concrete, Applied Sciences 7 (2017) 585:1-15.

[20] S.-Y. Chung, M. A. Elrahman, P. Sikora, T. Rucinska, E. Horszczaruk, D. Stephan, Evaluation of the effects of crushed and expanded waste glass aggregates on the material properties of lightweight concrete using imagebased approaches, Materials 10 (2017) 1354.

[21] G. Huesken, H. J. H. Brouwers, A new mix design concept for earth-moist concrete: A theoretical and experimental study, Cement and Concrete Research 35 (2008) 1246-1259.

[22] E. K. K. Nambiar, K. Ramamurthy, Airvoid characterisation of foam concrete, Cement and Concrete Composites 37 (2007) 221-230.

[23] Z. Huang, T. Zhang, Z. Wen, Proportioning and characterization of portland cement-based ultra-lightweight foam concretes, Construction and Building Materials 79 (2015) 390-396.

[24] S. K. Lim, C. S. Tan, O. Y. Lim, Y. L. Lee, Fresh and hardened properties of lightweight foamed concrete with palm oil fuel ash as filler, Construction and Building Materials 46 (2013) 39-47. 
[25] P. Zhihua, L. Hengzhi, L. Weiqing, Preparation and characterization of super low density foamed concrete from Portland cement and admixtures, Construction and Building Materials 72 (2014) 256-261.

[26] A. A. Hilal, N. H. Thom, A. R. Dawson, On void structure and strength of foamed concrete made without/with additives, Construction and Building Materials 85 (2015) 157-164.

[27] T. T. Nguyen, H. H. Bui, T. D. Ngo, G. D. Nguyen, Experimental and numerical investigation of influence of air-voids on the compressive behaviour of foamed concrete, Materials and Design 130 (2017) $103-119$.

[28] A. A. Sayadi, J. V. Tapia, T. R. Neitzert, G. C. Clifton, Effects of expanded polystyrene (EPS) particles on fire resistance, thermal conductivity and compressive strength of foamed concrete, Construction and Building Materials 112 (2016) 716-724.

[29] Z. Zhang, J. L. Provis, A. Reid, H. Wang, Mechanical, thermal insulation, thermal resistance and acoustic absorption properties of geopolymer foam concrete, Cement and Concrete Composites 62 (2015) 97-105.

[30] T.-C. Ling, C.-S. Poon, Use of phase change materials for thermal energy storage in concrete: An overview, Construction and Building Materials 46 (2013) 55-62.

[31] D. M. A. Huiskes, A. Keulen, Q. L. Yu, H. J. H. Brouwers, Design and performance evaluation of ultralightweight geopolymer concrete, Materials and Design 89 (2016) 516-526.

[32] EN 197-1, Cement - Part 1: Composition, specifications and conformity criteria for common cements (Sep. 2011).

[33] EN 13263-1, Silica fume for concrete - Part 1: Definitions, requirements and conformity criteria (Feb. 2009).

[34] M. A. Elrahman, S.-Y. Chung, D. Stephan, Effect of different expanded aggregates on the lightweight concrete properties, Magazine of Concrete Research DOI: 10.1680/jmacr.17.00465.

[35] Y. H. M. Amran, N. Farzadnia, A. A. A. Ali, Properties and applications of foamed concrete; a review, Construction and Building Materials 101 (2015) 990-1005.

[36] EN 12350-6, Testing fresh concrete. density (Jan. 2009).

[37] Z. He, L. Li, S. Du, Creep analysis of concrete containing rice husk ash, Cement and Concrete Composites 80 (2017) 190-199.

[38] T. Bellezze, D. Timofeeva, G. Guiliani, G. Roventi, Effect of soluble inhibitors on the corrosion behaviour of galvanized steel in fresh concrete, Cement and Concrete Composites 107 (2018) 1-10. 
[39] D. Fukuda, Y. Nara, Y. Kobayashi, M. Maruyama, M. Koketsu, D. Hayashi, H. Ogawa, K. Kaneko, Investigation of self-sealing in high-strength and ultra-low-permeability concrete in water using micro-focus X-ray CT, Cement and Concrete Research 42 (2012) 1494-1500.

[40] S.-Y. Chung, T.-S. Han, Correlation between low-order probability distribution functions and percolation of porous concrete, Magazine of Concrete Research 65 (2013) 448-460.

[41] N. Otsu, A threshold selection method from gray-level histograms, Man and Cybernetics 9 (1979) 62-66.

[42] D.-Y. Huang, C.-H. Wang, Optimal multi-level thresholding using a two-stage otsu optimization approach, Pattern Recognition Letters 30 (2009) 275-284.

[43] DIN EN 12390-7:2009, Testing hardened concrete - part 7: Density of hardened concrete (Jul. 2009).

[44] DIN EN 12390-4:2000, Testing hardened concrete-Part 4: Compressive strength; specification for testing machines (Jul. 2000).

[45] DIN EN 12390-5:2009, Testing hardened concrete. flexural strength of test specimens (May 2009).

[46] ISO 22007-2:2015, Plastics-determination of thermal conductivity and thermal diffusivity-part 2: Transient plane heat source (Hot Disk) method (Aug. 2015).

[47] Y. He, Rapid thermal conductivity measurement with a hot disk sensor: Part 1. Theoretical considerations, Thermochimica Acta 436 (2005) 122-129.

[48] S.-Y. Chung, M. A. Elrahman, D. Stephan, P. H. Kamm, Investigation of characteristics and responses of insulating cement paste specimens with Aer solids using X-ray micro-computed tomography, Construction and Building Materials 118 (2016) 204-215.

[49] E. Gallucci, K. Scrivener, A. Groso, M. Stampanoni, G. Margaritondo, 3d experimental investigation of the microstructure of cement pastes using synchrotron X-ray microtomography, Cement and Concrete Research 37 (2007) 360-368.

[50] N. Bossa, P. Chaurand, J. Vicente, D. Borschneck, C. Levard, O. A. Chariol, J. Rose, Micro- and nano-X-ray computed-tomography: A step forward in the characterization of the pore-network of a leached cement paste, Cement and Concrete Research 67 (2015) 138-147. 
[51] T.-S. Han, X. Zhang, J.-S. Kim, S.-Y. Chung, J.-H. Lim, C. Linder, Area of lineal-path function for describing the pore microstructures of cement paste and their relations to the mechanical properties simulated from $\mu$-ct microstructures, Cement and Concrete Composites 89 (2018) 1-17. 